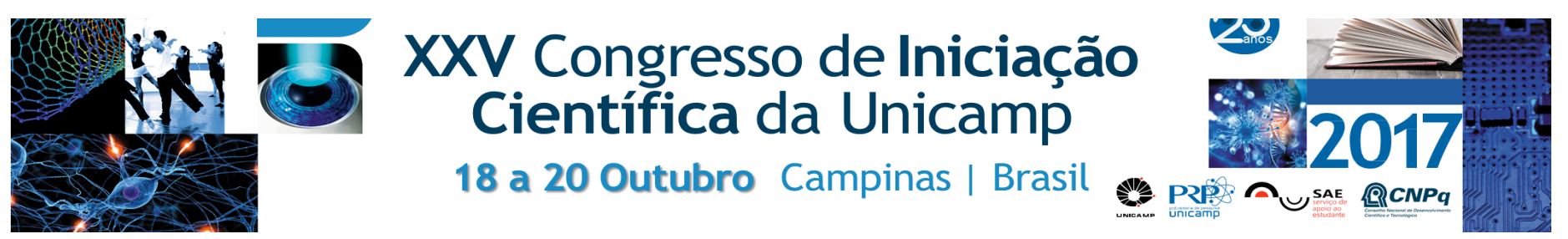

\title{
DIFERENÇAS CULTURAIS E PSICOLÓGICAS ENTRE ATLETAS UNIVERSITÁRIOS BRASILEIROS E IRLANDESES
}

\author{
Larissa K. G. Almeida*, Júlia P. Salazar, Júlia Barreira Augusto, Paula T. Fernandes
}

\section{Resumo}

O presente estudo teve como objetivo avaliar e comparar as diferenças psicológicas dos atletas universitários da Irlanda e do Brasil, discutindo as diversidades culturais dos dois países acerca desta temática. Os participantes da pesquisa foram 73 jovens de ambos os sexos entre 18 e 25 anos, sendo 41 brasileiros e 32 irlandeses. São alunos de diferentes cursos de universidades irlandesas e brasileiras, participantes de equipes esportivas de suas respectivas universidades. Os instrumentos utilizados para a coleta de dados foram: Escala de Autoestima de Rosenberg e Escala de Resiliência. Os resultados apontaram uma diferença pequena, porém não estatisticamente significativa entre as médias dos escores de autoestima e resilência dos atletas de diferentes países. Na Irlanda, os campeonatos e ligas universitárias são mais estruturados; enquanto no Brasil o esporte universitário ainda carece de investimento. Concluímos que, a gestão e organização do esporte universitário, evidentemente distinta entre os dois países, não tem repercutido na autoestima e resiliência dos jovens. Deixamos portanto, o questionamento: se tais fatores políticos e econômicos não repercutem no indivíduo, onde se encontram os reais reflexos da atual gestão e organização do esporte universitário brasileiro?

\section{Palavras-chave:}

Esporte universitário, psicologia do esporte, resiliência

\section{Introdução}

A universidade possui um importante papel na formação do indivíduo, tanto como profissional como membro de uma sociedade. Este ambiente, vivido de forma tão intensa, torna-se responsável por transmitir e promover a saúde psicológica do jovem estudante. Tornam-se evidentes as lacunas na sua estruturação, pesquisa e financiamento, tratando-se portanto, de algo relacionado ao lazer do estudante e não a uma vitrine para descobrimento de atletas. Já na Irlanda, assim como em países de primeiro mundo, o esporte é parte vital da vida universitária, não faltam investimentos e extrapolam os muros da universidade. Quanto aos aspectos psicológicos relacionados à atividade física, autoestima e resiliência são fatores determinantes para o bem-estar dos jovens e são influenciadas por estruturas culturais, sociais e de relações interpessoais. Dessa maneira, o objetivo deste estudo é mapear a autoestima e a resiliência de atletas universitários brasileiros e irlandeses, buscando possíveis diferenças entre os dois países.

\section{Resultados}

Participaram deste estudo 73 jovens com idade média de 23 anos (41 brasileiros e 32 irlandeses), de ambos os sexos, participantes de equipes esportivas de suas respectivas universidades. Os jovens responderam questionários contendo: Ficha de identificação, Escala de Autoestima e Escala de Resiliência. A partir dos resultados, percebemos que há uma diferença pequena, porém não estatisticamente significativa entre as médias dos escores de autoestima e de resilência dos atletas de diferentes países.

Tabela 1. Características de resiliência e autoestima de atletas brasileiros e irlandeses.

\begin{tabular}{|l|c|c|c|}
\hline & Brasil $(\mathbf{n}=\mathbf{4 1})$ & Irlanda $(\mathbf{n}=\mathbf{3 2})$ & Valor de $\mathbf{p}$ \\
\hline Resiliência & $130.2(13.7)$ & $132.4(12.7)$ & $\mathrm{p}=0.4847$ \\
\hline Autoestima & $8.4(4.8)$ & $10.2(4.5)$ & $\mathrm{p}=0.0973$ \\
\hline
\end{tabular}

\section{Resultados (cont.)}

Ao comparar resiliência e autoestima entre sexo masculino e feminino de diferentes nacionalidades, encontramos uma pequena diferença, principalmente na resiliência dos jovens do sexo masculino $(p=0,092)$, porém não estatisticamente significativa.

Tabela 2. Resiliência e Autoestima entre os jovens brasileiros e irlandeses (feminino e masculino).

\begin{tabular}{|l|c|c|c|c|}
\hline & \multicolumn{2}{|c|}{ Feminino } & \multicolumn{2}{c|}{ Masculino } \\
\hline & Brasil & Irlanda & Brasil & Irlanda \\
\hline Resiliência & $\begin{array}{c}130.9 \\
(13.6)\end{array}$ & $129.1(15.3)$ & $\begin{array}{c}129.5 \\
(14.2)\end{array}$ & $136.6(6.7)$ \\
\hline Autoestima & $8.9(4.9)$ & $11.4(5.1)$ & $7.9(4.7)$ & $8.8(3.3)$ \\
\hline
\end{tabular}

Ao analisar outras variáveis (modalidades coletivas ou individuais) para ambos os países, também não foram encontradas diferenças estatisticamente significativas.

\section{Discussão e Conclusões}

Destacamos a importância de mais questionamentos sobre a influência da qualidade e da sistematização do esporte universitário, por parte de uma cultura, no psicológico e eventual motivação dos jovens para o esporte. Ainda assim, salientamos que o Brasil ainda carece de sistematização e investimento no esporte universitário, para que seu potencial seja aproveitado ao máximo e que os estudantes possam usufruir deste sistema para além de uma atividade recreacional, mas que possa também servir como porta de entrada para o esporte de elite e descobrimento de novos talentos. Esperamos, por fim, que esse estudo possa servir para incentivar o esporte universitário no Brasil ou, pelo menos, estimular outras investigações acerca do mesmo tema.

\section{Agradecimentos}

PIBIC - CNPq; Universidade Estadual de Campinas; Dublin City University 